Revista Iberoamericana, Vol. LXXVI, Núm. 230, Enero-Marzo 2010, 11-21

\title{
BRASIL, BRASIS, OU: \\ A HORA E A VEZ DAS MINORIAS ÉTNICAS
}

POR

Cristina Ferreira-Pinto Bailey

Regina ZiLberman

“O QUE TEMOS NÓS COM ESSA RAÇA?”

Em uma das declarações mais politicamente incorretas de sua existência, Machado de Assis (1839-1908) lançou a seguinte pergunta no ensaio "O passado, o presente e o futuro da literatura”: "O que temos nós com essa raça, com esses primitivos habitadores do país, se os seus costumes não são a face característica da nossa sociedade?” (Machado de Assis, “O passado” 785). A questão era exposta no bojo da discussão sobre O Uraguai, de Basílio da Gama (1740-1795), obra celebrizada pelos historiadores da literatura das primeiras décadas do século dezenove, tais como Ferdinand Denis, Almeida Garrette Fernandes Pinheiro(Denis, 1823; Garrett, 1998; Pinheiro, 1862), por representar o que de mais nacional tinha, até então, alcançado a poesia brasileira.

Escreve Machado de Assis duas linhas antes da pergunta reproduzida no parágrafo anterior: "Sem trilhar a senda seguida pelos outros, Gama escreveu um poema, se não puramente nacional, ao menos nada europeu". A seguir, explica porque considera pouco nacional a epopéia de autoria de Basílio: "Não era nacional, porque era indígena, e a poesia indígena, bárbara, a poesia do boré e do tupã, não é a poesia nacional”. Conclui, enfim, o pensamento, rejeitando a relação que "nós" podemos ter com "eles", a raça dos "primitivos habitadores do país” (785).

Machado de Assis, nascido em 1839, publicou "O passado, o presente e o futuro da literatura”, entre 9 e 23 de abril de 1858, quando ainda não tinha vinte anos. O jovem rapaz, porém, militava na imprensa desde 1855, colaborando com Paula Brito (1809-1861) na Marmota Fluminense por intermédio da publicação de poemas, contos, crônicas e crítica literária. Mostrava-se, já nesse período, visivelmente insatisfeito com os rumos da literatura brasileira, e basta ler a afirmação acima para se constatar que o Indianismo não contava com sua admiração, embora essa orientação da poética nacional então andasse em alta no Rio de Janeiro, graças sobretudo a Gonçalves Dias (1823-1864) e a José de Alencar (1829-1877), 
responsáveis pelo sucesso dos Primeiros cantos, de autoria do primeiro, obra de 1847, e de $O$ guarani, do segundo, que a imprimira em folhetim e, a seguir, em livro, durante o ano de 1857.

Aos olhos e ouvidos do século vinte e um, soa mal e de modo incômodo a frase pronunciada pelo principal escritor brasileiro do século dezenove e ainda nosso principal nome literário. Talvez ela já tenha sido embaraçosa à época, pois Machado de Assis não a repete, quando torna a abordar a trajetória da literatura nacional em dois ensaios da década de 1870: a "Notícia da atual literatura brasileira", conhecido por seu subtítulo, "Instinto de nacionalidade”, de 1873, e "A nova geração”, de 1879. Em "Instinto da nacionalidade", ensaio inegavelmente redigido à sombra de "O passado, o presente e o futuro da literatura", o crítico ameniza sua posição, observando ser "certo que a civilização brasileira não está ligada ao elemento indiano, nem dele recebeu influxo algum” (132), anotação que lhe permite uma conclusão de ordem poética: "isto basta para não ir buscar entre as tribos vencidas os títulos da nossa personalidade literária” (Machado de Assis, "Instinto” 132). Mesmo essa exclusão é matizada, já que concede que "tudo é matéria de poesia", desde que "traga as condições do belo ou os elementos de que ele se compõe" (Machado de Assis, "Instinto" 132). Em “A nova geração", por sua vez, o tema desaparece inteiramente, embora Machado não perca a oportunidade de se referir a Basílio da Gama e a Tomas Antônio Gonzaga, autores que o perseguem desde a elaboração do estudo, já citado, de 1858.

Transcorridos 150 anos desde a pergunta colocada por Machado de Assis em seu ensaio, talvez posssamos dar a resposta: sim, temos a ver com essa raça, a dos “primitivos habitadores do país”. Aliás, temos também a ver com as demais raças, inclusive com aquela a que pertenceu o autor de Dom Casmurro, pois elas tomaram parte na construção do país, ou, nas palavras do ensaísta, na construção da "face característica da nossa sociedade”.

Vale complementar que a resposta à argüição de Machado de Assis não significa apenas a afirmação de uma tese que o escritor talvez gostasse de ver negada. Representa também a recusa de um sintagma utilizado por ele, que se refere à "face característica da nossa sociedade”, pois, com efeito, não se trata de uma, mas de distintas e plurais facetas, quando se fala da formação étnica e cultural brasileira.

Entende-se, porém, porque o escritor brasileiro aborda o tema no singular. Machado, que, tal como seus contemporâneos, nasceu, cresceu e amadureceu à época em que a jovem nação recentemente independizada de Portugal (a autonomia datava de 1822, e sua consolidação dera-se nas décadas de 1840 e 1850) procurava construir para si uma identidade e provavelmente acreditava na unidade do país. Além disso, afirmar o pluralismo naquele período seria como reabrir feridas ainda não inteiramente cicatrizadas, provocadas pelos conflitos regionais no Sul, no Nordeste

\footnotetext{
Revista Iberoamericana, Vol. LXXVI, Núm. 230, Enero-Marzo 2010, 11-21 ISSN 0034-9631 (Impreso) ISSN 2154-4794 (Electrónico)
} 
e no Norte do Brasil, conhecidos pelos apelidos que tomaram naqueles tempos, como a guerra dos Farrapos, no Rio Grande do Sul, a Balaiada, no Maranhão, ou a Cabanagem, no Pará, para lembrar alguns deles.

O princípio da unidade nacional repercutia na literatura, garantida, já se vê, por muitas exclusões históricas, a começar pela exclusão de diferentes raças que participaram da edificação da sociedade brasileira.

Para que a pergunta capciosa de Machado de Assis pudesse receber uma resposta afirmativa foi preciso deixar passar o tempo. Talvez não devesse ser assim, se a sociedade brasileira tivesse se mostrado mais democrática e menos colonizada, seja no passado distante vivido por Machado de Assis e seus parceiros, seja mesmo em períodos relativamente recentes. Por causa dela, o autor de "Instinto da nacionalidade”, reproduzindo atitude então (e mesmo depois) assumida pela intelectualidade brasileira, refere-se aos indígenas como "raça extinta, tão diferente da raça triunfante" ("Instinto" 132), esta sendo, por conseqüência, a portuguesa, responsável pela ocupação do território americano e pela povoação.

Aceitar o pluralismo racial e étnico significou, portanto, dar largas passadas históricas. Primeiramente, foi necessário acolher as legiões de imigrantes que chegaram ao Brasil após a independência, formadas por: contingentes de portugueses que se deslocavam à América em busca de trabalho ou de melhores condições de exercerem suas atividades intelectuais, como ocorreu ao futuro cunhado do próprio Machado de Assis, Faustino Xavier de Novais (1820-1869), que, depois, estimulou a irmã, Carolina Xavier de Novais (1835-1904), a viajar do Porto ao Rio de Janeiro, onde encontrou seu futuro marido; grupos de alemães trazidos, ainda à época de D. Pedro I (1798-1834), pela esposa deste, Maria Leopoldina de Habsburgo (1797-1826), que, na condição de imperatriz do Brasil, deu início, nos anos 1820, ao deslocamento de populações de origem germânica ao sul do país, processo que tomou as décadas subseqüentes durante o século dezenove; grande número de italianos, transferidos sobretudo para as regiões de plantação de café, onde deveriam substituir o trabalhador de origem africana, já que a escravatura caminhava para a extinção. A esses núcleos populacionais, somaram-se, no começo do século vinte, japoneses, judeus eárabes, que foram ocupando setores diferenciados da economia - a agricultura, o comércio, a indústria - e distintas áreas da geografia nacional, espalhando-se, assim, do Sul ao Norte do país.

Depois, tornou-se imprescíndivel adotar sistema político que representasse efetivamente a totalidade da população residente no Brasil. Não bastou apenas passar da monarquia à república, o que ocorreu ao final do século dezenove, mas, principalmente, adotar o voto universal. Eis um processo que avançou lentamente durante o século vinte, começando pelo reconhecimento do voto feminino, em 1932, e, depois, estendendo esse direito a todos os cidadãos maiores de 16 anos,

Revista Iberoamericana, Vol. LXXVI, Núm. 230, Enero-Marzo 2010, $11-21$
ISSN 2154-4794 (Electrónico) 
sem qualquer restrição, conforme advoga a Constituição Brasileira, vigente desde 1988.

A revisão histórica deu-se na esteira de tais acontecimentos, como também na esteira de movimentos políticos reivindicatórios que, passada a primeira metade do século vinte, varreram o mundo ocidental, chegando na América Latina. Assim, por exemplo, o movimento feminista dos anos 1960, o movimento norteamericano pelos direitos civis e os movimentos de independência das nações africanas repercutiram no Brasil, e influenciaram a ação político-cultural de vários segmentos da sociedade brasileira. A partir desse quadro de transformações sociais e políticas, portanto, trata-se de reconhecer não apenas a diversidade étnica no Brasil de hoje, mas sua presença nas várias etapas da trajetória da vida nacional. As manifestações culturais absorveram esse novo posicionamento e trataram de expressá-lo, de que são testemunhos não apenas as expressões da literatura, do cinema e da televisão, por exemplo, mas também as pesquisas no plano das Ciências Humanas. Os estudos literários, a historiografia, a antropologia - eis algumas áreas de conhecimento que atualmente se debruçam sobre as questões étnicas quando refletem sobre a construção da identidade nacional e suas representações artísticas, culturais, políticas e ideológicas.

O que foi, à época de Machado de Assis, exclusão ou ocultamento é, em nossos tempos, matéria de discussão e reivindicação, expondo, de modo crítico e criativo, a organização múltipla da sociedade brasileira, graças à qual, inclusive, o criador de Bentinho e Capitu pôde se transformar, de descendente de escravos, em escritor livre.

NOVO DISCURSO LITERÁRIO

O ideal de uma raça única foi perseguido pelos românticos e pelos intelectuais "pós-românticos" das primeiras décadas do século vinte engajados num projeto de definição de uma identidade nacional muito própria, mas sempre à altura de uma unidade nacional que os brasileiros percebiam na pátria-avó portuguesa e nas outras nações européias. Como afirmou David T. Haberly em sua importante obra Three Sad Races (1983), o intelectual brasileiro profundamente comprometido com o projeto de definição da nacionalidade, mantinha ainda seu olhar virado para a Europa, "toward Portugal and the racial and cultural unity Portugal represents" (50). A miscigenação e a imagem do brasileiro como resultado da união das três matrizes raciais - a portuguesa, a índia e a negra - pareciam responder a esse ideal de unidade, servindo tanto "as the explanation for Brazil's racial and cultural diversity" como "as a metaphor for the formation of a distinctive national civilization” (Haberly 168).

\footnotetext{
Revista Iberoamericana, Vol. LXXVI, Núm. 230, Enero-Marzo 2010, 11-21 ISSN 0034-9631 (Impreso) ISSN 2154-4794 (Electrónico)
} 
Entretanto, a mestiçagem, ou o melting pot brasileiro, revela-se tão problemática como a ideologia da democracia racial propagada a partir da obra-mestre de Gilberto Freyre, Casa-grande e senzala, de 1933, pois, como já foi apontado por vários críticos, ambas atuam como mecanismos ideológicos ao serviço da hegemonia de um grupo, permitindo a exclusão, o borramento ou a assimilação dos outros. Uma vez examinada criticamente, a idéia de mestiçagem, justaposta à da democracia racial, apresenta-se como uma máscara de cordialidade a esconder o perfil multicultural da sociedade brasileira, perfil complexo e marcado por tensões e conflitos.

Nas últimas décadas do século vinte, a sociedade brasileira, segundo a análise correta de Edimilson de Almeida Pereira e Stephen F. White, procura afirmar e dar expressão a suas múltiplas imagens, discutindo "how multicultural or multiracial aspects can contribute to the formation of an identity based on the coexistence of several racial groups" (Pereira e White 123-24). Desse modo, o conceito de um mosaico étnico apresenta-se como mais adequado para representar o perfil identitário multicultural da nação brasileira, enquanto que a idéia de mestiçagem terá de ser revisada para deixar de ser sinônimo do ocultamento de uns e hegemonia de outros.

O mosaico brasileiro começa a formar-se com maior nitidez a partir da segunda metade do século dezenove na esteira da onda migratória iniciada por alemães e italianos, a que se seguiram os japoneses e os judeus do centro da Europa, aportados em Santos nas primeiras décadas do século vinte. Europeus e asiáticos vinham somar-se aos povos que fizeram parte da história colonial brasileira e americana: indígenas, cuja população diminui consideravelmente ao longo dos séculos, e negros, trazidos de África para o trabalho escravo nas lavouras, na mineração e na extração de matérias-primas, além, claro, dos colonizadores portugueses.

Foram os europeus desembarcados na leva do século dezenove que motivaram um novo filão literário, explorado a partir dos anos 1930, como mostra, por exemplo, a ficção de Erico Verissimo (1905-1975), onde se encontram representantes dos diferentes povoadores do território dominado pela metrópole portuguesa. Italianos, alemães e judeus já comparecem na fiç̧ão produzida pelo escritor sulino naquela década; quando, em 1949, Verissimo publica O Continente, primeiro volume da trilogia $O$ tempo e o vento, negros e indígenas aparecem na linha de frente da formação racial sulina, metonímia da formação racial brasileira.

Outros romancistas da mesma geração, que consolidaram o chamado romance de 30, avançaram significativamente no processo de representação do leque étnico brasileiro. Jorge Amado (1912-2001), por exemplo, compôs um panorama diversificado, de que seu romance Gabriela, cravo e canela, de 1958, protagonizado pela mulata do título, coadjuvada pelo árabe Nacib, é testemunha. É, contudo, nas últimas décadas do século vinte que uma mudança se faz notar na trajetória da

\footnotetext{
Revista Iberoamericana, Vol. LXXVI, Núm. 230, Enero-Marzo 2010, 11-21 ISSN 0034-9631 (Impreso) ISSN 2154-4794 (Electrónico)
} 
literatura brasileira, condizente com o processo político e ideológico, citado antes, de democratização mais ampla da sociedade nacional: em obras produzidas nesse período, o que se percebe não é apenas a presença de personagens marcadas por sua pertença a determinado grupo migratório ou a uma dada etnia; é que a literatura contemporânea se define pelas questões geradas por essa pertença.

Por conseqüência, o que parecia pacífico tornou-se problemático, fazendo com que a literatura - e demais expressões artísticas da cultura, como o cinema ou o teatro - tenha de buscar outra linguagem para dar conta da questão que se apresenta. É muito diferente colocar uma personagem de origem judaica ou moura em uma obra ou deixá-la manifestar-se autonomamente. O resultado é um discurso que não se caracteriza apenas pela novidade, mas também por sua natureza freqüentemente contestadora e revolucionária.

Os ensaios aqui reunidos debruçam-se sobre as vozes dos vários grupos étnicos que se fazem ouvir na literatura brasileira. Essa diversidade de vozes não só responde à pergunta de Machado de Assis que abriu esta introdução, mas responde também à questão, O que é ser brasileiro? Como se define esse povo e a que tipo de preocupações e aspirações dá expressão em sua obra criativa? Estes ensaios, abarcando os gêneros narrativo - narrativa literária e cinemática - poético e ensaístico, dão conta de que existem múltiplas versões da nacionalidade, versões essas muitas vezes contraditórias ou mesmo conflitivas, o que reflete uma sociedade multicultural e atuante, em contínuo processo de transformação.

Abre a primeira parte deste volume o ensaio de Regina Félix sobre Brava gente brasileira (2000), filme de Lúcia Murat sobre os índios Guaikuru que problematiza a historiografia europeizante no que diz respeito à participação dos indígenas brasileiros no processo de formação da nação. Félix detem-se não só na experiência dos renomados guerreiros em um momento fundacional da terra brasileira, como justapõe essa experiência eminentemente masculina à experiência e à contribuição da mulher indígena, destacando e contrapondo vários planos discursivos. Dessa forma, Félix aponta para aquela "zona de contato" (termo de Mary Louise Pratt) mais fundamental - entre homem e mulher - que o filme de Murat privilegia ao reescrever a história da fundação.

Outra "zona de contato" é objeto de estudo no ensaio de Silvana Seabra sobre Caminhos e fronteiras (1957) de Sérgio Buarque de Holanda. O livro, ensaio de caráter etnográfico sobre a expansão paulista em direção ao oeste brasileiro, expressa ainda o projeto identitário modernista que caracterizou a obra anterior de Buarque de Holanda. O estudo de Seabra apresenta vários pontos de interesse. Além de analisar Caminhos e fronteiras como obra literária, Seabra salienta também a idéia da nação que o autor inscreve, ou seja, a identidade nacional como o somatório de suas partes regionais, elemento que, aliás, situa esse livro na esteira do Modernismo de Mário

\footnotetext{
Revista Iberoamericana, Vol. LXXVI, Núm. 230, Enero-Marzo 2010, 11-21 ISSN 0034-9631 (Impreso) ISSN 2154-4794 (Electrónico)
} 
de Andrade ilustrado em Macunaíma (1928). Essa zona de contato que Buarque de Holanda esmiúça revela-se, segundo Seabra, uma "zona babélica” onde interagem e se chocam elementos culturais, regionais e temporais vários. Como recorte do que foi o processo de colonização de todo o país, aí se presencia também - e assim anota Buarque de Holanda - o contágio cultural e lingüístico, a "mistura sutil e complexa”, como caracterizou Silviano Santiago, que permitiria "uma espécie de infiltração progressiva efetuada pelo pensamento selvagem, ou seja, abertura do único caminho possível que poderia levar à descolonização” (Santiago 15).

Esse lento processo de descolonização tem lugar ainda hoje, e os ensaios deste volume são dele testemunhas. Cabe, entretanto, demarcar cada estágio seu, como o faz Regina Zilberman ao discorrer sobre a imagem dos judeus ao longo da literatura brasileira. Zilberman examina as representações dos judeus na literatura brasileira a partir de duas grandes vertentes que ela identifica na literatura ocidental: uma com origens bíblicas, na figura de Moisés, e outra com origens na Idade Média, tendo no judeu usurário sua figura emblemática. Após examinar essas duas vertentes nas obras dos românticos Gonçalves de Magalhães, Castro Alves e José de Alencar, a ensaísta examina o romance de Moacyr Scliar, Os vendilhões do templo (2006), como uma obra revisionista que resgata a figura do judeu ao relacionar o episódio bíblico da entrada de Jesus no templo à história colonial brasileira e ao momento atual que vive a nação.

A participação do judeu na formação da cultura brasileira é revista também por Patricia Nuriel. De novo um romance de Scliar aparece como objeto de análise, desta vez O ciclo das águas, de 1977. A partir do ensaio de Nuriel pode-se comprovar uma constante que orienta vários dos ensaios aqui reunidos: não só a revisão histórica e a reinscrição de vários protagonistas antes ocultos ou minimizados devido à sua identidade étnica, mas também o destaque dado às figuras femininas e à sua contribuição ao processo de formação da nacionalidade. Aqui Nuriel examina a história da protagonista de Scliar, Esther Markowitz, e a contextualiza dentro do quadro histórico do tráfico de prostitutas judias que se estabeleceu entre a Europa e o Brasil e a Argentina a finais do século dezenove e princípios do vinte. Ressaltese, além disso, a história de Marcos, filho de Esther, pertencente a uma primeira geração de judeus brasileiros. Se Marcos representa, como afirma Nuriel, uma etapa mais avançada num processo de aculturação (borramento? ocultamento da herança não-católica portuguesa?), ele ilustra também a problemática da língua, a língua portuguesa que ele, ao contrário da sua mãe, domina, mas que já vem, queira-se ou não, “contaminada”. Marcos encarna assim o novo, a nova nação, um processo social que, segundo Scliar - e ao contrário do que parece sugerir o título de seu romance - deixa de ser cíclico para abrir-se às infinitas possibilidades de transformação.

$\begin{array}{lllll}\text { Revista Iberoamericana, Vol. LXXVI, Núm. 230, Enero-Marzo 2010, } & 11-21 \\ \text { ISSN 0034-9631 (Impreso) }\end{array}$ 
Parafraseando Bernardo Soares, um dos heterônimos de Fernando Pessoa, Caetano Veloso afirma: "Minha pátria é minha língua”. Essa língua, o português brasileiro, "roça” (Veloso, "Língua”) a língua de Camões mas, como comprova a canção, é muito mais rica porque contaminada, híbrida, incorpora elementos e palavras de outras culturas e línguas. Pablo Gasparini examina a contaminação lingüística empregada como estratégia literária e que é também instrumento identitário. O autor examina primeiramente a autobiografia de Vilém Flusser, imigrante checo que chega ao Brasil em 1940. O exame da obra de Flusser e de sua teoria e prática da tradução permite um acercamento instigante à situação do imigrante e a uma questão que torna-se um tropo recorrente na literatura pósmoderna: o deslocamento geográfico e cultural e seu impacto sobre um sentido de identidade do sujeito. Essa acaba constituindo-se como uma identidade em movimento ou fronteiriça.

Essa identidade fronteiriça expressa-se também nas obras de dois outros escritores: Alexandre Ribeiro Marcondes Machado, conhecido por seu pseudônimo Juó Bananère, e Wilson Bueno. Em todos verifica-se o que Gasparini chama de "desbordamento" de uma língua a outra - seja o checo ou alemão e o português em Flusser; o português paulistano marcado pelo italiano em Bananère; ou o "portunhol" em Wilson Bueno - o que resulta em uma língua "de entremedio”, expressiva da identidade fronteiriça ou em movimento do sujeito.

Se essa identidade "em movimento" ou “em deslocamento" vai ser característica do sujeito pós-moderno, ela érealidade já durante o processo de colonização, quando elementos de várias culturas e etnias vêm encontrar-se no Novo Mundo. O ensaio de Antonio R. Esteves e María Antonia Zandanel enfoca esse sujeito em quatro romances históricos - exemplos de metaficção historiográfica, para usar o termo de Linda Hutcheon - de autores vários, publicados na última década do século vinte. Três desses romances enfocam o período colonial, enquanto que o último, Videiras de cristal (1991), do gaúcho Luiz Antonio de Assis Brasil, trata de um episódio ocorrido a finais do século dezenove e conhecido como a "Guerra dos Muckers", movimento messiânico suprimido de maneira violenta pelo governo federal, à maneira do que ocorreu em Canudos. Na análise de Esteves e Zandanel sobressai a importância que as personagens femininas adquirem nesses romances, o que revela uma preferência revisionista que, característica da narrativa pós-moderna, tem a dever aos estudos literários de cunho feminista, já que essas obras privilegiam uma revisão histórica a partir de uma perspectiva “da cozinha”, a contrapelo da visão historiográfica épica da formação da nacionalidade.

Susan C. Quinlan, em ensaio de fôlego, analisa outro romance histórico pós-moderno, A república dos sonhos (1984) de Nélida Piñon, obra que também privilegia a experiência feminina ao contar a experiência do imigrante. Piñon propõe

\footnotetext{
Revista Iberoamericana, Vol. LXXVI, Núm. 230, Enero-Marzo 2010, 11-21 ISSN 0034-9631 (Impreso) ISSN 2154-4794 (Electrónico)
} 
uma revisão feminista da história e uma nova forma de entendermos a formação da nacionalidade, a partir da experiência de sujeitos duplamente marginais, como imigrantes e como mulheres dentro de espaços dominados pelo patriarcalismo: a nação e a família.

Apesar de o enfoque de A república dos sonhos recair principalmente sobre a experiência dos imigrantes galegos, o romance oferece também uma visão da experiência da mulher negra de uma classe menos privilegiada e sua situação dentro da família patriarcal branca. Entretanto, a experiência dos afro-brasileiros, contada por eles mesmos, vai ser amplamente discutida por Lizbeth Souza-Fuertes a partir da atuação literária dos membros do Quilombhoje. Souza-Fuertes analisa poemas e ensaios de vários nomes ligados aos Cadernos negros, detendo-se sobretudo na obra de Cuti, uma das vozes mais importantes e influentes da literatura afro-brasileira contemporânea. Em sua poesia, assim como em entrevistas, depoimentos e outros escritos, Cuti levanta questões prementes quanto à situação do sujeito negro na sociedade brasileira, entre elas o problema do racismo, a mestiçagem e a ideologia do branqueamento. Embora ressaltando a obra de Cuti, Souza-Fuertes apresenta um quadro bastante completo dos escritores que participaram dos Cadernos negros desde os seus primórdios, não esquecendo tampouco do papel fundamental de alguns pioneiros da literatura negra brasileira, como Cruz e Souza, Lino Guedes e Solano Trindade. Se a literatura afro-brasileira, como afirma Souza-Fuertes, tem como objetivo reescrever a história para nela afirmar a participação do negro, por tanto tempo escamoteada pela historiografia oficial, ela alcança revisar também a questão do que é ser brasileiro.

Perspectivas diversas sobre o que é ser brasileiro e como se define a identidade nacional aparecem nos ensaios que se seguem. Lidia Santos trata do que poderíamos chamar, juntamente com Silviano Santiago, o "cosmopolitismo do pobre”, ${ }^{1}$ um cosmopolitismo "por necessidade”, nas palavras da autora. Examinando o romance Relato de um certo Oriente (1996) de Milton Hatoum, paralelamente aos textos de seringueiros, especificamente Chico Mendes e Zeca Tiago, Santos acerca-se à questão da nacionalidade a partir do regionalismo amazônico e da identidade dos chamados “povos da floresta”, chamando atenção para a dimensão internacional e cosmopolita que alcança o trabalho dos dois ativistas políticos. Esse cosmopolitismo encontra-se presente no romance de Hatoum, cuja ficção tem enfocado a população de ascendência libanesa no estado do Amazonas. O tratamento contrastivo dos gêneros da literatura testemunhal (Mendes e Tiago) e da romanesca (Hatoum) propõe uma “reinvenção” do regionalismo brasileiro, enquanto destaca, por um lado, problemas éticos e políticos atuais e, por outro, a inserção de etnias várias na composição

1 Faz-se referência aqui, obviamente, ao ensaio de Santiago, "O cosmopolitismo do pobre" ( $O$ cosmopolitismo do pobre, de Silviano Santiago, Belo Horizonte: Editora UFMG, 2004, 45-63).

Revista Iberoamericana, Vol. LXXVI, Núm. 230, Enero-Marzo 2010, $11-21$
ISSN 2154-4794 (Electrónico) 
identitária da nação. Tanto os textos de Mendes e Tiago como o romance de Hatoum constroem um retrato da Amazônia caracterizado por contrastes e conflitos - de etnias, de idiomas e registros lingüísticos, como também de classe social.

Em seu estudo sobre $O$ sol se põe em São Paulo (2007) de Bernardo Carvalho, Sandra Sousa retoma a problemática de identidades fronteiriças ou "em deslocamento", como ela as chama. Desta vez, enfoca-se a problemática do brasileiro de ascendência japonesa que vive uma situação conflitiva no "entre-lugar" das culturas japonesa e brasileira, um brasileiro cujos traços orientais o caracterizam como japonês mas que encontra no português brasileiro sua pátria. Dividido entre as duas culturas nas quais se criou, o protagonista do romance de Carvalho vive a experiência do não pertencimento, tanto em sua própria terra - o Brasil - como no Japão, para onde se desloca temporariamente. Trabalhando com o jogo de máscaras e de nomes que já havia explorado em livros anteriores, Carvalho apresenta a situação das primeiras gerações de imigrantes japoneses no Brasil e a sua contrapartida: a experiência dos nipo-brasileiros no Japão. Santos explora principalmente o jogo dos nomes, para verificar até que ponto um nome está relacionado ao estabelecimento de uma identidade pelo sujeito e como o autor problematiza a identidade nacional a partir da experiência de seu protagonista.

O último ensaio do volume, de Cristina Ferreira-Pinto Bailey, remete-nos de volta ao primeiro, ao examinar a obra de Eliane Potiguara, escritora e ativista política que tem trabalhado em prol dos direitos dos povos indígenas brasileiros. Ao apresentar uma outra perspectiva sobre a experiência dos primeiros povos que habitaram a nação brasileira, este ensaio dialoga não só com o de Félix, que abriu o volume, como também com outros estudos aqui reunidos, pois retoma pontos importantes levantados anteriormente, destacando-se entre eles: a experiência da mulher pertencente a um grupo étnico minoritário; a problemática do deslocamento do sujeito; e a revisão da história, com o objetivo de afirmar a participação de um sujeito que - se não foi completamente excluído - teve sua participação na formação da nacionalidade frequentemente minimizada e infantilizada.

A pergunta inicial de Machado de Assis, "O que temos nós com essa raça?" reescreve-se na questão que orienta cada um destes ensaios: “O queéser brasileiro?”. Ou seja, como definirmos a nação se esta, na realidade, apresenta-se heterogênea e pluricultural, formada pelo encontro de sujeitos de etnias diversas, que, embora constituindo uma entidade única que compartilha uma língua comum, são marcados, como é de se esperar, por influências várias e fortes. Existem várias maneiras de ser brasileiro, e os ensaios deste volume oferecem apenas um pequeno panorama de como a literatura brasileira tem respondido essa questão. As entrevistas e depoimento de três autores brasileiros contemporâneos, ficcionistas e poetas, Daniel Munduruku, Moacyr Scliar e Jussara Santos, complementam a parte de

\footnotetext{
Revista Iberoamericana, Vol. LXXVI, Núm. 230, Enero-Marzo 2010, 11-21 ISSN 0034-9631 (Impreso) ISSN 2154-4794 (Electrónico)
} 
ensaios críticos, oferecendo perspectivas atuais, não só sobre a questão específica da nacionalidade, como também sobre problemas como o racismo, a discriminação de gênero e a diferença que, ainda hoje, continuam influenciando a maneira como nós brasileiros nos definimos.

\section{OBRAs CITADAS}

Denis, Ferdinand. Resumo de história literária do Brasil. Guilhermino César, trad. Porto Alegre: Lima, 1968.

Garrett, Almeida. "Bosquejo da história da poesia e língua portuguesa”. O berço do cânone. Regina Zilberman e Maria Eunice Moreira, orgs. Porto Alegre: Mercado Aberto, 1998. 29-73.

Haberly, David T. Three Sad Races. Racial Identity and National Consciousness in Brazilian Literature. Cambridge: Cambridge UP, 1983.

Machado de Assis, Joaquim Maria. "Instinto de nacionalidade”. Crítica Literária. São Paulo: Mérito, 1959. 129-49.

“A nova geração”. Crítica literária. São Paulo: Mérito, 1959. 180-244.

"O passado, o presente e o futuro da literatura”. Obra completa. Vol. 3. Rio de Janeiro: Aguilar, 1958. 785-89.

Pereira, Edimilson de Almeira, e Stephen F. White. "Brazil: Interactions and Conflicts in a Multicultural Society”. Global Multiculturalism: Comparative Perspectives on Ethnicity, Race, and Nation. Grant H. Cornwell e Eve Walsh Stoddard, eds. Lanham, MD: Rowman \& Littlefield, 2001. 123-41.

Pinheiro, Joaquim Caetano Fernandes. Curso elementar de literatura nacional. Rio de Janeiro: Garnier, 1862.

Santiago, Silviano. "O entre-lugar do discurso latino-americano". Uma literatura nos trópicos: ensaios sobre dependência cultural. $2^{\text {a }}$. ed. Rio de Janeiro: Rocco, 2000. 9-26.

Veloso, Caetano. "Língua”. Velô. Polygram, 1984. CD.

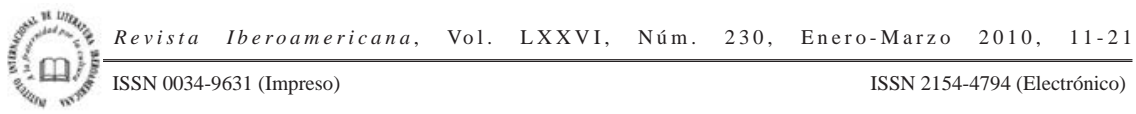


